\title{
Case report: IgG4-related renal disease co-existing with retroperitoneal fibrosis
}

\author{
Young Jin Kim ${ }^{1}$, Ga-Eon $\mathrm{Kim}^{2}$, Seong Kwon $\mathrm{Ma}^{1}$, Soo Wan Kim ${ }^{1}$, Eun Hui Bae ${ }^{1}$ \\ ${ }^{1}$ Department of Internal Medicine, Chonnam National University Medical School, Gwangju, South Korea; ${ }^{2}$ Department of Pathology, Chonnam \\ National University Medical School, Gwangju, South Korea \\ Correspondence to: Eun Hui Bae, MD, PhD. Department of Internal Medicine, Chonnam National University Medical School, 42 Jebongro, Gwangju \\ 61469, South Korea. Email: baedak@hanmail.net.
}

\begin{abstract}
A 51-year-old woman visited our clinic for orthopnea, chest discomfort, and facial and leg edema. Acute kidney injury and pleural effusion were diagnosed and she received hemodialysis. This is a rare case of IgG4-related disease diagnosed by renal biopsy in the patient with retroperitoneal fibrosis and severe acute kidney injury, which progressed rapidly and required hemodialysis without markedly elevated serum IgG4 level and urinary tract obstruction. Immunostaining of a kidney biopsy revealed IgG4-related renal disease and magnetic resonance imaging showed retroperitoneal fibrosis in the paraspinal and presacral areas. After 3 days of glucocorticoid treatment, renal function and bilateral pleural effusion were restored. Another 2 months of glucocorticoid treatment decreased the extent of retroperitoneal fibrosis on follow-up abdominal computed tomography. IgG4-related disease is a recently recognized fibro-inflammatory condition with a dense lymphoplasmacytic infiltration of IgG4-positive plasma cells. The kidney and retroperitoneum are the frequently associated organs in IgG4-related disease. This case shows that IgG4-related disease can involve the kidney and/or other organs and be diagnosed by kidney biopsy.
\end{abstract}

Keywords: IgG4-related renal disease; retroperitoneal fibrosis; case report; acute kidney injury; kidney biopsy

Submitted Oct 18, 2019. Accepted for publication Jan 17, 2020.

doi: $10.21037 /$ tau.2020.02.06

View this article at: http://dx.doi.org/10.21037/tau.2020.02.06

\section{Introduction}

IgG4-related disease is a recently recognized fibroinflammatory condition with a dense lymphoplasmacytic infiltration of IgG4-positive plasma cells. IgG4-related disease can involve various organs of humans (1). Retroperitoneal fibrosis was first described by Dr. John Ormond in 1948. It is a rare disease with fibro-inflammatory changes in the soft tissues in the retroperitoneal space (2). The kidney and retroperitoneum are frequently associated organs in IgG4-related disease (3). Although elevated serum IgG4 levels are not always specific for IgG4related disease, the elevation of IgG4 level often correlates with the activity of the disease and the number of organs involved (4-6). This is a rare case of IgG4-related disease diagnosed by renal biopsy without markedly elevated serum IgG4 level. Sometimes the clinical manifestations accompanying retroperitoneal fibrosis give an idea of the underlying condition of this disease. We herein report a case of IgG4-related disease which involves the kidney and retroperitoneum.

\section{Case presentation}

A 51-year-old woman visited our hospital for chest discomfort, orthopnea, and edema in the face and both legs. She had a medical history of hypertension, diabetes mellitus, and uterine myoma. No abnormal physical finding was presented except pitting edema on both lower extremities. Her baseline creatinine was $0.50 \mathrm{mg} / \mathrm{dL}$ (normal range, $0.5-1.3 \mathrm{mg} / \mathrm{dL}$ ) a month ago. On admission day, her serum creatinine was elevated at $1.44 \mathrm{mg} / \mathrm{dL}$ (Table 1 ). Her urinalysis exam showed hematuria without proteinuria. Chest X-ray revealed bilateral pleural effusion (panel A 
Table 1 Laboratory findings on admission

\begin{tabular}{|c|c|}
\hline Laboratory parameters (Units) & Results [Normal ranges] \\
\hline \multicolumn{2}{|l|}{ Complete blood cell count } \\
\hline White blood cells $\left(\times 10^{3} / \mu \mathrm{L}\right)$ & $6,900[4,800-10,800]$ \\
\hline Hemoglobin (g/dL) & $9.4[12-18]$ \\
\hline Platelet count $\left(\times 10^{3} / \mu \mathrm{L}\right)$ & $282[130-450]$ \\
\hline \multicolumn{2}{|l|}{ Blood chemistry } \\
\hline BUN (mg/dL) & $16.5[8-23]$ \\
\hline Creatinine (mg/dL) & $1.44[0.5-1.3]$ \\
\hline Sodium (mEq/L) & $140[135-145]$ \\
\hline Potassium (mEq/L) & $3.5[3.5-5.1]$ \\
\hline Chloride (mEq/L) & 110 [98-110] \\
\hline Total protein (g/dL) & $7.4[6-8.3]$ \\
\hline Albumin (g/dL) & $3.4[3.5-5.2]$ \\
\hline CRP (mg/dL) & $2.37[0-0.3]$ \\
\hline Troponin I (ng/mL) & $0.007[0-0.05]$ \\
\hline ProBNP (pg/mL) & $851.2[0-270]$ \\
\hline LDH (U/L) & 600 [218-472] \\
\hline \multicolumn{2}{|l|}{ Urinalysis } \\
\hline Specific gravity & $<1.005$ [1.005-1.03] \\
\hline $\mathrm{pH}$ & $5.5[5-8]$ \\
\hline Protein & Negative \\
\hline Glucose & Negative \\
\hline Ketone body & Negative \\
\hline Red blood cell & $30-49 / \mathrm{HPF}$ \\
\hline Casts & Negative \\
\hline \multicolumn{2}{|l|}{ Immunoglobulins } \\
\hline ANA & Nucleolar: $80[1+]$ \\
\hline ANCA & Negative \\
\hline $\lg G(\mathrm{mg} / \mathrm{dL})$ & $1,731.5[700-1,600]$ \\
\hline $\lg A(m g / d L)$ & $498.4[70-400]$ \\
\hline $\lg M(m g / d L)$ & $109.0[40-230]$ \\
\hline $\lg \mathrm{E}(\mathrm{IU} / \mathrm{mL})$ & $11.7[1.5-158]$ \\
\hline IgG4 subclass (mg/dL) & 93.07 [3.90-86.40] \\
\hline
\end{tabular}

BUN, blood urea nitrogen; CRP, C-reactive protein; proBNP, pro-brain natriuretic peptide; $L D H$, lactate dehydrogenase; ANA, antinuclear antibody; ANCA, antineutrophil cytoplasmic autoantibody; Ig, immunoglobulin. of Figure 1). Kidney ultrasonography showed increased cortical echogenicity with mild hydronephrosis (grade 1) (Figure 2) (7). Enhanced pelvic magnetic resonance imaging (MRI) showed an ill-defined soft tissue lesion with low signal intensity on $\mathrm{T} 1$ weighted image and relatively homogeneous enhancement on contrast-enhanced image, in the paraspinal and presacral area. These imaging studies did not suggest an obstructive lesion in both urinary tracts prominently, and her urine volume was maintained over 1.5 L/day. Thoracentesis was performed twice and the aspirated pleural fluid was a transudate (Table 2). The nonenhanced CT scan of the chest did not show a significant lesion, except pleural effusion. Despite of management for acute kidney injury, serum creatinine was increased at $9.22 \mathrm{mg} / \mathrm{dL} 10$ days after admission and urine output was decreased. We inserted a permanent jugular catheter and performed hemodialysis.

A kidney biopsy was performed, which showed inflammatory cell infiltration consisting of lymphocytes and mast cells. Hematoxylin \& eosin stain, Periodic acidSchiff stain and Masson trichrome stain of kidney specimen was obtained and they showed dense lymphoplasmacytic infiltration (Figure 3A,B,C). More than 10 IgG4-positive plasma cells were observed per high power field in the immunostaining of kidney biopsy specimens with monoclonal antibodies for IgG4 (Figure 3D). Regretfully, the serum IgG level was not increased significantly $(1,731.5 \mathrm{mg} / \mathrm{dL}$, reference range $700-1,600 \mathrm{mg} / \mathrm{dL})$, as well as serum IgG4 subclass level $(93.07 \mathrm{mg} / \mathrm{dL}$, reference range $3.90-86.40 \mathrm{mg} / \mathrm{dL}$ ). We performed positron emission tomography-computed tomography (PET-CT) with ${ }^{18}$ fluorodeoxyglucose to rule out malignancy, it revealed a diffuse hypermetabolic soft tissue lesion along the retroperitoneal space without lymph node, lung or pleural involvement (Figure 4). The pathologic diagnosis for this kidney biopsy was compatible with IgG4-related kidney disease and radiologic diagnosis indicated retroperitoneal fibrosis.

We started $60 \mathrm{mg}$ of prednisolone $(1 \mathrm{mg} / \mathrm{kg} /$ day $)$ for 3 days and her renal function improved rapidly from 9.22 to $1.22 \mathrm{mg} / \mathrm{dL}$. After the administration of $30 \mathrm{mg} / \mathrm{day}$ of prednisolone for 12 days, serum creatinine was decreased to $0.6 \mathrm{mg} / \mathrm{dL}$, and pleural effusion disappeared (Figure $1 B$ and Figure 5). Two months after discharge, she underwent abdominal CT, which showed a decreased extent of the illdefined soft tissue lesion involving both the paraspinal area 

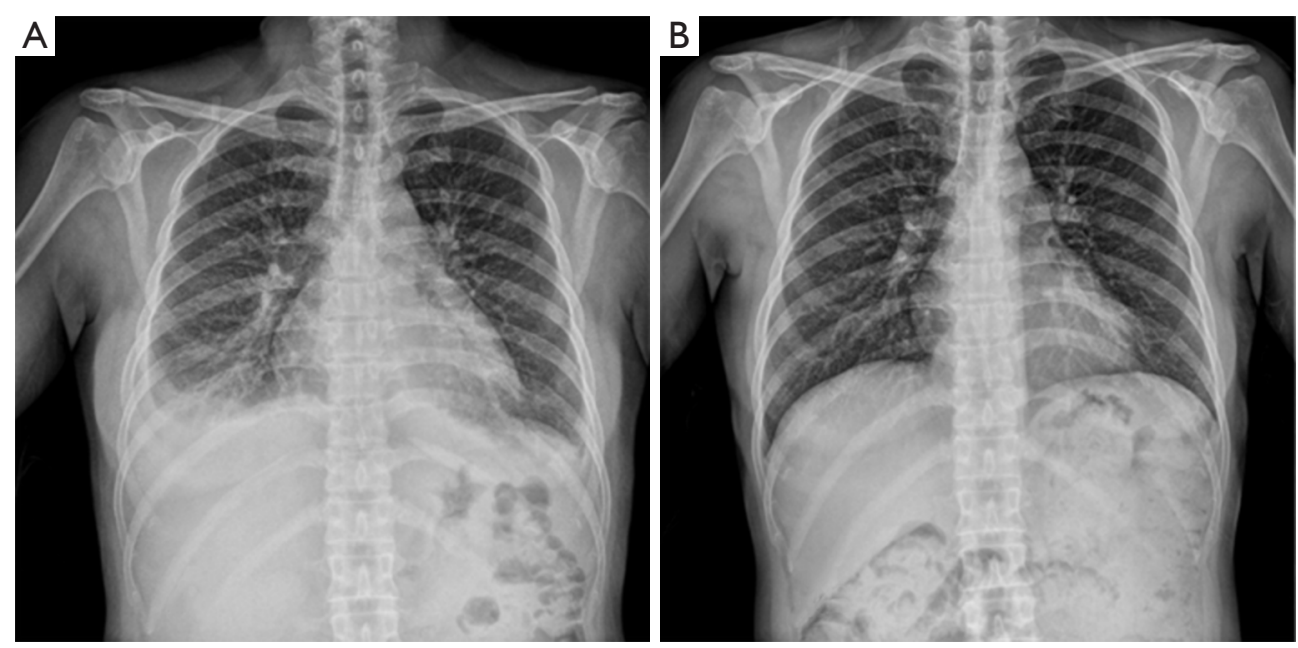

Figure 1 Chest X-rays before and after treatment. (A) Bilateral pleural effusion and pulmonary edema on chest simple X-ray. (B) Pleural effusion and pulmonary edema was disappeared after treatment.

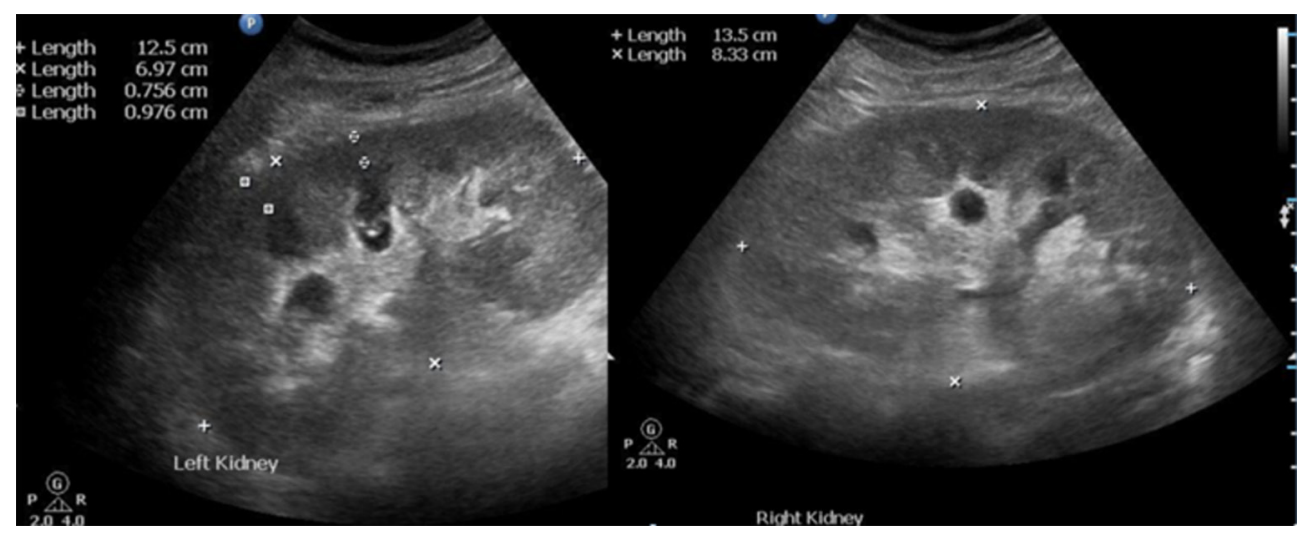

Figure 2 Kidney ultrasonography. Kidney ultrasonography showing increased cortical echogenicity with mild bilateral hydronephrosis (grade 1).

Table 2 Pleural fluid analysis

\begin{tabular}{lc}
\hline Laboratory parameters (Units) & Results \\
\hline Total nucleated cells $\left(\mathrm{mm}^{-3}\right)$ & 503 \\
Red blood cells $\left(\mathrm{mm}^{-3}\right)$ & 600 \\
White blood cells $\left(\mathrm{mm}^{-3}\right)$ & 314 \\
Polymorphonuclear leukocytes & $2.2 \%$ \\
Mononuclear cells & $97.8 \%$ \\
Specific gravity & 1.015 \\
pH & 7.471 \\
Glucose (mg/dL) & 214 \\
Lactate dehydrogenase (U/L) & 232 \\
Protein (g/dL) & 3.0 \\
\hline
\end{tabular}

of L5 and the presacral space (Figure 6). We maintained 10 $\mathrm{mg}$ of prednisolone during another 4 months for preventing relapse. She was followed up every month and showed good adherence and tolerance for treatment. Steroidinduced diabetes occurred, but it was well-controlled by the administration of oral hypoglycemic agents. She expressed satisfaction with the treatment and the response.

\section{Discussion}

We reported a case of $\mathrm{IgG} 4$-related disease with renal and retroperitoneal complications. IgG4-related disease was identified as a systemic condition in patients with autoimmune pancreatitis and extra-pancreatic manifestations in 2003 for the first time $(1,6)$. The 

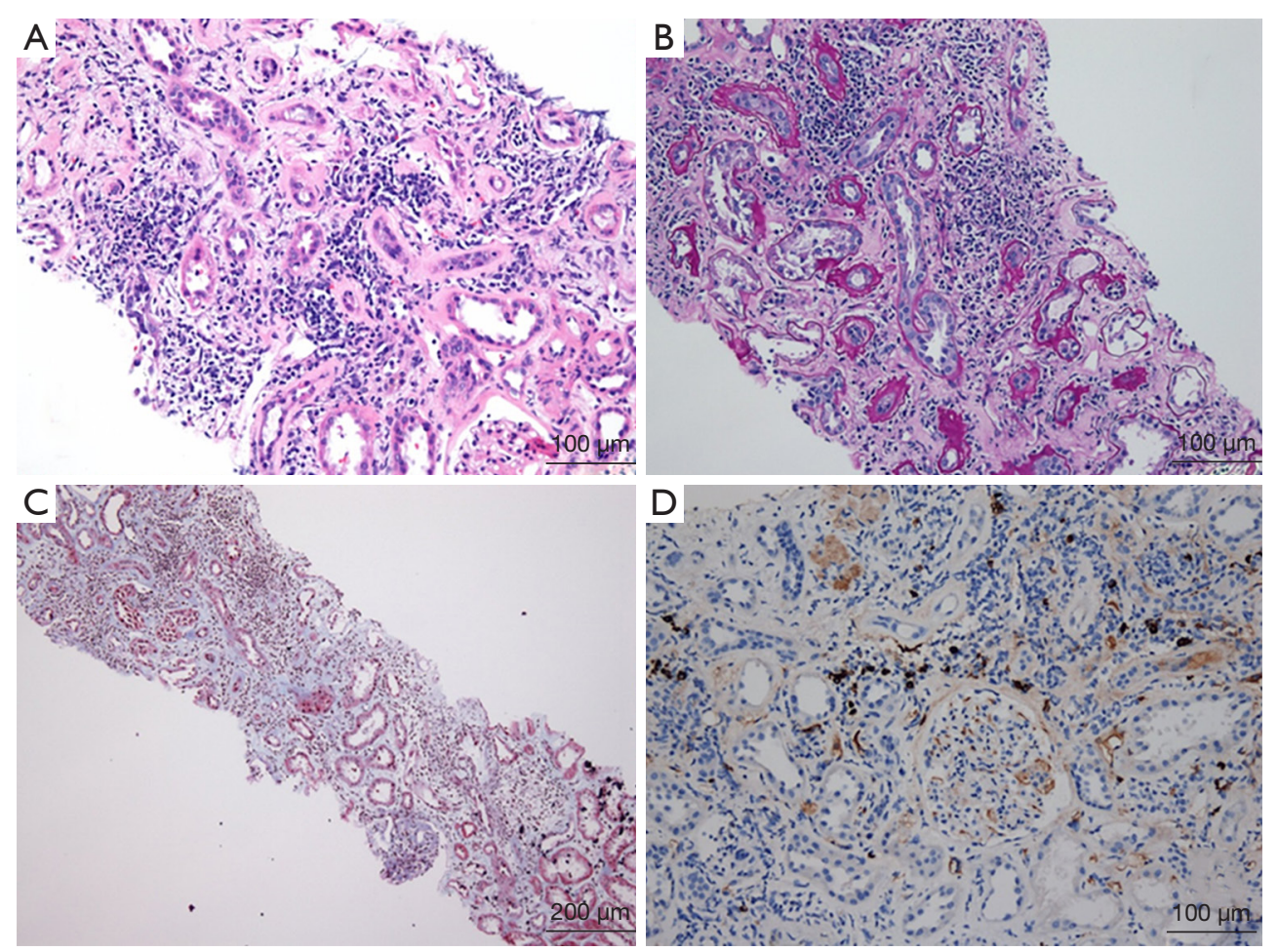

Figure 3 Kidney biopsy. A tissue specimen form kidney biopsy showed a dense lymphoplasmacytic infiltration (A, hematoxylin and eosin stain, $\times 200$; B, Periodic acid-Schiff stain, $\times 200$; C, Masson trichrome stain, $\times 100$ ). Immunohistochemical staining for IgG4 monoclonal antibody showed more than 10 IgG4-positive plasma cells per high-power field in the peritubular interstitial area $(\mathrm{D}, \times 200)$.

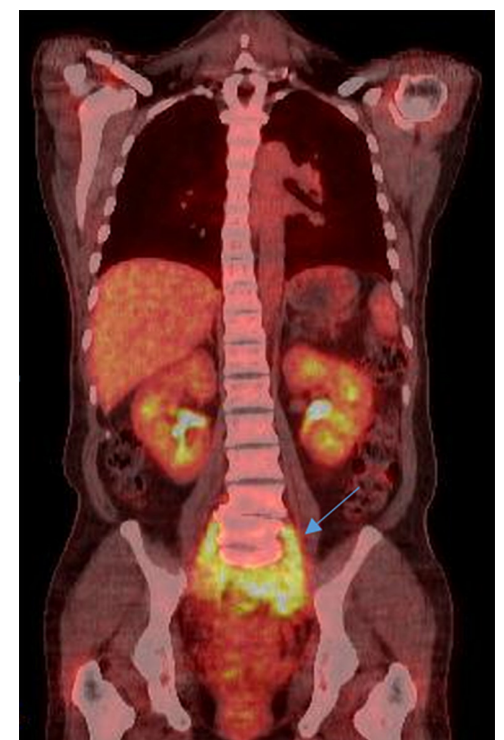

Figure 4 Positron emission tomography-computed tomography (PET-CT). PET-CT with ${ }^{18}$ fluorodeoxyglucose revealed a diffuse hypermetabolic soft tissue lesion along the retroperitoneal space (arrow). There was no significant hypermetabolism in the lung and pleura. frequency of renal involvement is $7.0 \%$ to $24.6 \%$ and that of retroperitoneal involvement is $9.6 \%$ to $27.0 \%$ in patients with IgG4-related disease (8-10). Two small studies in America and Japan represented that $57-59 \%$ of idiopathic retroperitoneal fibrosis were IgG4-related (11). And in a small retrospective study in South Korea, $59.3 \%$ of patients diagnosed idiopathic retroperitoneal fibrosis were found as IgG4-related (12). IgG4-related diseases are not always associated with an elevation of serum IgG4 concentration. Even if the serum IgG4 level was not significantly elevated in this case, an infiltration of IgG4-positive plasma cells in biopsy tissue could indicate a diagnosis of IgG4-related renal disease (1). IgG4-related renal disease is one of the most frequent forms of organ involvements in IgG4related disease, and the most common type of IgG4-related renal disease is tubulointerstitial nephritis. Glomerular disease such as membranous glomerulonephritis, and renal pelvic lesion like IgG4-related pyelitis can be presented as other types of IgG4-related renal disease. Without glomerular lesions, IgG4-related renal disease leads to very mild or no symptoms in most patients. It usually 


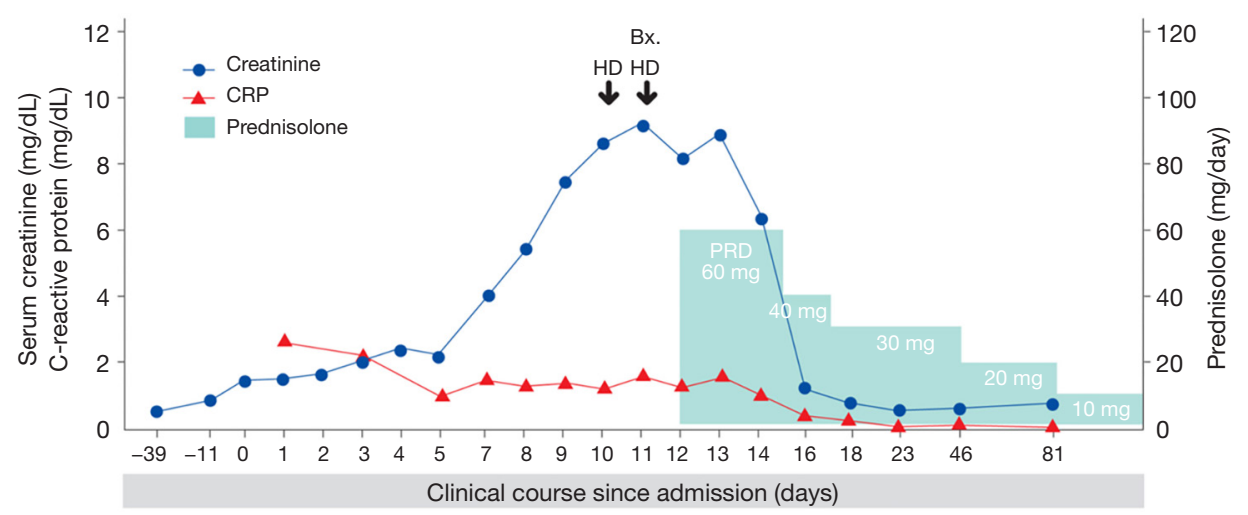

Figure 5 Clinical course of IgG4 related renal disease. HD, hemodialysis; Bx., Kidney biopsy; PRD, prednisolone; CRP, C-reactive peptide.
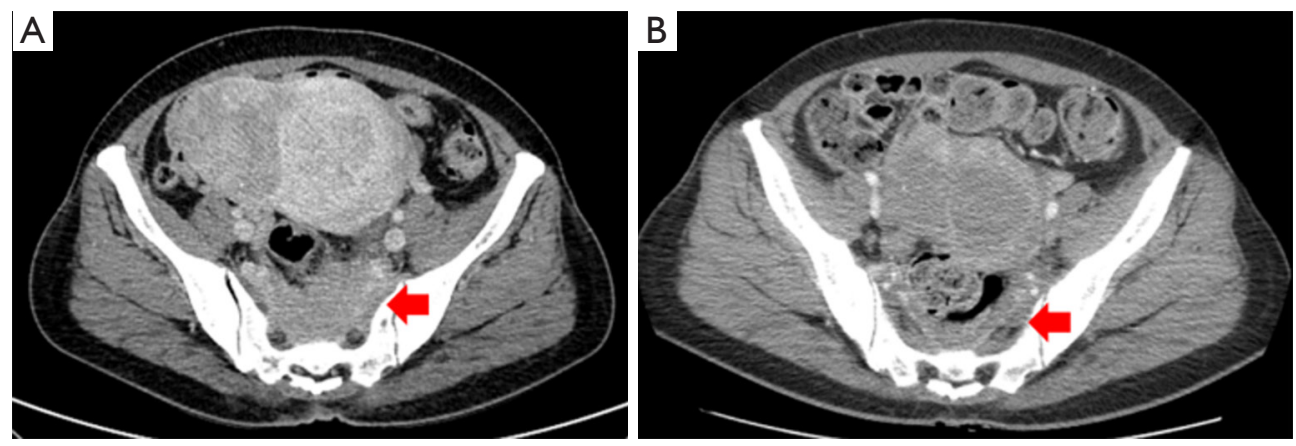

Figure 6 Enhanced CT scans of the abdomen, before and after treatment. Enhanced CT scan of the abdomen revealed diffuse prevertebral soft tissue thickening and enhancement at lower lumbar spine and sacrum (A, arrow). The CT scan after treatment showed a decreased extent of the ill-defined soft tissue lesion involving both the paraspinal area of L5 and the presacral space (B, arrow).

presents mild proteinuria less than $500 \mathrm{mg} / \mathrm{gCr}$ with or without hematuria. Retroperitoneal fibrosis associated with IgG4-related disease shows bilateral hydronephrosis in $25 \%$ of reported cases, and unilateral hydronephrosis in $75 \%$ of cases (8). In this patient, a post-renal obstructive lesion was not significant in various radiologic and ultrasound findings. And only 2 sessions of hemodialysis and 3 days of administration of glucocorticoids were needed for fast recovery from acute kidney injury, without any intervention such as percutaneous nephrostomy or ureteric stent insertion. The treatment of choice is glucocorticoids, $0.6 \mathrm{mg} / \mathrm{kg} /$ day of prednisolone, for 2 to 4 weeks. Then prednisolone can be tapered to $2.5-5 \mathrm{mg} /$ day for 3 to 6 months $(1,13-15)$. Glucocorticoids show a good response in the majority of patients, but flare-up of the disease often occurs $(1,8,10-12)$. Several drugs like Rituximab, azathioprine, mycophenolate mofetil, and methotrexate can be used for refractory disease or for preventing relapse $(1,15-18)$. We successfully diagnosed IgG4-related renal disease and retroperitoneal fibrosis by kidney biopsy without findings suggesting IgG4-related disease such as the elevation of serum IgG4 level or abnormal imaging findings, and controlled them without significant adverse effects by administrating glucocorticoid. Nevertheless, this case has some limitations. We did not perform surgical tissue biopsy of retroperitoneal fibrosis, itself. In addition, pleural effusion cytology and pleural biopsy were not conducted, so we could not check the possibility of accompanied IgG4-related pulmonary disease.

In conclusion, we successfully diagnosed and managed this case of IgG4-related renal disease with retroperitoneal fibrosis by glucocorticoid treatment. Retroperitoneal fibrosis can be a clue for hidden IgG4-related disease when manifestations in other organs are present, like acute kidney injury and pleural effusion. 


\section{Acknowledgments}

Funding: This study was supported by a grant (BCRI18024\&20025) from Chonnam National University Hospital Biomedical Institute.

\section{Footnote}

Conflicts of Interest: All authors have completed the ICMJE uniform disclosure form (available at http://dx.doi. org/10.21037/tau.2020.02.06). The authors have no conflicts of interest to declare.

Ethical Statement: The authors are accountable for all aspects of the work in ensuring that questions related to the accuracy or integrity of any part of the work are appropriately investigated and resolved. Written informed consent was obtained from the patient for publication of this Case report and any accompanying images.

Open Access Statement: This is an Open Access article distributed in accordance with the Creative Commons Attribution-NonCommercial-NoDerivs 4.0 International License (CC BY-NC-ND 4.0), which permits the noncommercial replication and distribution of the article with the strict proviso that no changes or edits are made and the original work is properly cited (including links to both the formal publication through the relevant DOI and the license). See: https://creativecommons.org/licenses/by-ncnd/4.0/.

\section{References}

1. Stone JH, Zen Y, Deshpande V. IgG4-related disease. N Engl J Med 2012;366:539-51.

2. Ormond JK. Bilateral ureteral obstruction due to envelopment and compression by an inflammatory retroperitoneal process. J Urol 1948;59:1072-9.

3. Cronin CG, Lohan D, Blake M, et al. Retroperitoneal fibrosis: a review of clinical features and imaging findings. AJR Am J Roentgenol 2008;191:423-31.

4. Cheuk W, Chan JK. IgG4-related sclerosing disease: a critical appraisal of an evolving clinicopathologic entity. Adv Anat Pathol 2010;17:303-32.

5. Hamano H, Kawa S, Horiuchi A, et al. High serum IgG4 concentrations in patients with sclerosing pancreatitis. $\mathrm{N}$ Engl J Med 2001;344:732-8.

6. Kamisawa T, Funata N, Hayashi Y, et al. A new clinicopathological entity of IgG4-related autoimmune disease. J Gastroenterol 2003;38:982-4.

7. Timberlake MD, Herndon C. Mild to moderate postnatal hydronephrosis-grading systems and management. Nat Rev Urol 2013;10:649-56.

8. Kawano M, Saeki T, Nakashima H. IgG4-related kidney disease and retroperitoneal fibrosis: An update. Mod Rheumatol 2019;29:231-9.

9. Nakashima H, Kawano M, Saeki T, et al. Estimation of the number of histological diagnosis for IgG4-related kidney disease referred to the data obtained from the Japan Renal Biopsy Registry (J-RBR) questionnaire and cases reported in the Japanese Society of Nephrology Meetings. Clin Exp Nephrol 2017;21:97-103.

10. Yamada K, Yamamoto M, Saeki T, et al. New clues to the nature of immunoglobulin G4-related disease: a retrospective Japanese multicenter study of baseline clinical features of 334 cases. Arthritis Res Ther 2017;19:262.

11. Lian L, Wang C, Tian J. IgG4-related retroperitoenal fibrosis: a newly characerized disease. Int J Rheum Dis 2016;19:1049-55.

12. Choi YK, Yang J, Ahn S, et al. Retroperitoneal fibrosis in the era of immunoglobulin G4-related disease. Kidney Res Clin Pract 2019;38:42-8.

13. Kamisawa T, Shimosegawa T, Okazaki K, et al. Standard steroid treatment for autoimmune pancreatitis. Gut 2009;58:1504-7.

14. Ghazale A, Chari ST, Zhang L, et al. Immunoglobulin G4-associated cholangitis: clinical profile and response to therapy. Gastroenterology 2008;134:706-15.

15. Salvadori M, Tsalouchos A. Immunoglobulin G4-related kidney diseases: An updated review. World J Nephrol 2018;7:29-40.

16. Kamisawa T, Zen Y, Pillai S, et al. IgG4-related disease. Lancet 2015;385:1460-71.

17. Khosroshahi A, Carruthers M, Deshpande V, et al. Rituximab for the treatment of IgG4- related disease: lessons from ten consecutive patients. Medicine (Baltimore) 2012;91:57-66.

18. Khosroshahi A, Bloch D, Deshpande V, et al. Rituximab therapy leads to rapid decline of serum IgG4 levels and prompt clinical improvement in IgG4related systemic disease. Arthritis Rheum 2010;62:1755-62.

Cite this article as: Kim YJ, Kim GE, Ma SK, Kim SW, Bae EH. Case report: IgG4-related renal disease co-existing with retroperitoneal fibrosis. Transl Androl Urol 2020;9(2):794-799. doi: $10.21037 /$ tau.2020.02.06 